\title{
Effect of Tryptophan Hydroxylase-2 rs7305115 SNP on suicide attempts risk in major depression
}

\author{
Yuqi Zhang ${ }^{1{ }^{*}}$, Changsong Zhang ${ }^{2 \dagger}$, Guozhen Yuan ${ }^{1 \dagger}$, Jianjun Yao ${ }^{1}$, Zaohuo Cheng ${ }^{1}$, Chaojun Liu ${ }^{3}$, Qinghai Liư ${ }^{3}$, \\ Gairong Wan ${ }^{3}$, Guizhi Shi ${ }^{4}$, Yiren Cheng ${ }^{3}$, Yang Ling ${ }^{2}$, Ke Li ${ }^{4}$
}

\begin{abstract}
Background: Suicide and major depressive disorders (MDD) are strongly associated, and genetic factors are responsible for at least part of the variability in suicide risk. We investigated whether variation at the tryptophan hydroxylase-2 (TPH2) gene rs7305115 SNP may predispose to suicide attempts in MDD.
\end{abstract}

Methods: We genotyped TPH2 gene rs7305115 SNP in 215 MDD patients with suicide and matched MDD patients without suicide. Differences in behavioral and personality traits according to genotypic variation were investigated by logistic regression analysis.

Results: There were no significant differences between MDD patients with suicide and controls in genotypic (AG and GG) frequencies for rs7305115 SNP, but the distribution of AA genotype differed significantly (14.4\% vs. 29.3\%, $p<0.001)$. The $\mathrm{G}$-allele frequency was significantly higher in cases than control group $(58.1 \% \mathrm{vs.45.6 \% ,} p<0.001)$, but the A-allele carrier indicated a decreased trend in MDD with suicide behaviors than control group (41.9\% vs.54.4\%, $p<0.001)$. The multivariate logistic regression analysis indicated that $\mathrm{TPH} 2 \mathrm{rs} 7305115 \mathrm{AA}(\mathrm{OR} 0.33,95 \% \mathrm{Cl}$ $0.22-0.99)$, family history of suicide $(\mathrm{OR} 2.98,95 \% \mathrm{Cl} 1.17-5.04)$, negative life events half year ago (OR $6.64,95 \% \mathrm{Cl}$ 2.48-11.04) and hopelessness (OR 7.68, 95\% Cl 5.79-13.74) were significantly associated with the suicide behaviors in MDD patients.

Conclusions: The study suggested that hopelessness, negative life events and family history of suicide were risk factors of attempted suicide in MDD while the TPH2 rs7305115A remained a significant protective predictor of suicide attempts.

\section{Background}

Suicide is an important public health problem and ranks among the top 10 causes of death for individuals of all ages and major depressive disorders (MDD) appeared to confer greater risk for suicide [1,2]. Suicidal behavior is commonly considered to result from an interaction of genetic, neurobiological, and psychosocial factors. Genetic risk factors are estimated to account for approximately $30 \%$ to $40 \%$ of the variance in suicidal behavior, however the precise mechanism of the genetic contribution are unknown [3].

Dysregulation of brain serotonin contributes to many psychiatric disorders. Furthermore, abnormal serotonergic function has frequently been reported in individuals

\footnotetext{
*Correspondence: hbzcs@126.com

† Contributed equally

'Wuxi Psychiatric Hospital, Nanjing Medical University, Wuxi, China

Full list of author information is available at the end of the article
}

who commit or attempt suicide and is one of the most replicated findings in modern biological psychiatry [4]. For example, low levels of serotonin (5-hydroxytryptamine, 5-HT) have also been observed in suicide victims and 5-HT could play a role in the predisposition to suicide [5]. Tryptophan hydroxylase (TPH), the rate limiting enzyme in the biosynthesis of 5-HT neurotransmission, is a major candidate for genetic association studies in many psychiatric disorders, including suicide [6,7]. Two genes coding TPH (TPH1 and TPH2) have been differentiated. The human TPH2 gene is located on chromosome 12q15, comprises 11 exons, and covers a region of about 93.5 kilobases (gene accession number: NM_173353). $\mathrm{TPH} 2$, rather than TPH1, is preferentially expressed in the brain [8]. TPH2 is neuron-specific and expressed predominantly in serotonergic neurons of the raphe nuclei and in the peripheral myenteric neurons in the gut $[9,10]$. The genetic polymorphisms affecting TPH2 gene 
expression might result in the alteration of physiological processes related to 5-HT. 5-HT is involved in the dysfunction of numerous psychiatric disorders and behavioral traits, such as MDD, suicide, or depression.

To date, nearly five hundred SNPs have been identified in human TPH2, most of them located in noncoding regions of the gene. However, a few functional polymorphisms have been reported. A functional (C1473G) SNP in mouse TPH2 that results in the substitution of Pro447 with Arg447 and leads to decreased serotonin levels in PC12 cells provides direct evidence for TPH2 controls brain serotonin synthesis [11]. Zill et al provides evidence for an involvement of genetic variants of the TPH2 gene in the pathogenesis of MDD and might be a hint on the repeatedly discussed duality of the serotonergic system [12]. The human TPH2 promoter polymorphism rs11178997 impacts on TPH2 expression, which might have implications for the development and function of the serotonergic system in the brain [13]. The TPH2 gene and its 5' upstream region variants (SNPs: rs4448731 and rs4641527) may be involved in the predisposition to suicide in MDD [14]. The core promoter of human TPH2 was localized to the region between -107 and +7 , and the segment of +8 to +53 within the 5 - UTR was found to exert a potent inhibitory effect on gene expression at both transcriptional and post-transcriptional levels [15]. The TPH2 C2755A polymorphism may represent a population-specific risk factor for peripartum major depression and anxiety disorder, perhaps by interacting with hormones in Chinese [16]. These results may open up new research strategies for the analysis of the observed disturbances in the serotonergic system in patients suffering from several other psychiatric disorders. Understanding the mechanisms of TPH2 gene polymorphism in suicide attempters may shed light on the neurobiology of the vulnerability to suicidal behavior and reveal potential targets of preventive and therapeutic actions.

In the current study, we investigated another TPH2 polymorphism named rs7305115 at approximately $1077 \mathrm{bp}$ from the 7 exon. To our knowledge, its functionality has not been studied so far. Therefore, the purpose of the present study was to detect possible association between rs7305115 polymorphisms of $\mathrm{TPH} 2$ gene and suicide behavior in MDD patients. We performed association and linkage disequilibrium studies on 215 MDD who committed suicide and 215 control MDD patients without suicide behavior. It could be an attempt to examine the association between different components-genetic, environmental, neurobiological, and behavioral of a complex, multivariate and heterogeneous phenomenon.

\section{Materials and methods}

\section{Patients and controls}

The sample investigated consisted of 430 unrelated MDD patients who were recruited from Mar 2004 to May 2008 in the Han nationality of Shandong Province, China. All patients (184 males, 246 females) hospitalized in psychiatric clinics in Shandong, China. Diagnosis of MDD should be confirmed by the Mini International Neuropsychiatric Interview and by a minimum score of Hamilton Depression Rating Scale (HDRS) [17,18]. All cases met DSM-IV diagnostic criteria for MDD and were severe enough to require follow-up in a specialized psychiatric outpatient clinic $[19,20]$. Axis I and Axis II psychopathologies were determined using the Structured Clinical Interview for DSM-IV Axis I Disorders (SCID-I) and the Structured Clinical Interview for DSM-IV Personality Disorders (SCID-II), respectively. The SCID was administered to all patient subjects by experienced psychiatrists. By means of structured questionnaires, information on specific demographic and clinical variables, such as family history of suicide and history of physical or sexual abuse, was also obtained.

Two hundred and fifteen MDD patients (defined as MDD+suicide group, 92 males, and 123 females) consecutively admitted to our psychiatric departments after a suicide were included in this study. The suicide patient was defined as intentional self-harm to end one's life but not die as a result of his/her action(s). Individuals were scored as positive for a history of suicide attempt only when medical records documented a severe attempt, a relative or partner con- firmed the history, or there was physical evidence confirming the history. We classified suicide methods as violent or nonviolent according to the classification used in previous study [21]. Drug overdose, carbon monoxide poisoning, and drowning were considered nonviolent. All other methods were classified as violent.

Two hundred and fifteen MDD control patients (defined as MDD-suicide group, 92 males, and 123 females) without suicide attempt, which were closely matched with individual patients in the suicidal group in terms of age and gender, were selected for this study. They met all the DSM-IV criteria for major depressive disorder and had HDRS scored of over 18. They had no previous history of suicide attempt or family history of suicide. The other exclusion criteria included evidence of alcohol or drug dependency, significant organic brain disease, and clinically significant somatic disease.

All cases and control subjects were the Han population and came from the same geographical area in eastern China. The protocol of the study was in accordance with the ethics standards of the committee on Human Experimentation of Nanjing Medical University. 


\section{Genotyping}

Venous blood was drawn and immediately frozen in aliquots at $-70^{\circ} \mathrm{C}$ or below until analyzed. For genotyping, genomic DNA was extracted from EDTA blood samples by using a commercial DNA extract kit, Wizard Genomic DNA purification kit (Promega, Madison, WI, USA). TPH2 rs7305115 SNP genotyping was performed by DNA sequencing. First, DNA was amplified by polymerase chain reaction (PCR). PCR were carried out in $25 \mathrm{ul}$ volumes containing $20 \mathrm{ng}$ genomic DNA, $0.4 \mathrm{mM}$ primers, $50 \mathrm{mM} \mathrm{KCL}, 10 \mathrm{mM}$ Tris $/ \mathrm{HCl}(\mathrm{pH} 8.3)$, $0.025 \%$ Tween $20,0.025 \mathrm{mg} / \mathrm{ml} \mathrm{BSA}, 1.5 \mathrm{mM}$ magnesium chloride, $0.4 \mathrm{mM} \mathrm{dNTP}$ and $1 \mathrm{U}$ Taq polymerase with the following oligonucleotide primers: forward 5'-ACCTGAGCCCACGAGACTTT-3'; reverse 5'TCGAGCCAGAGCTGGAATAT-3'. After an initial denaturation step for $5 \mathrm{~min}$ at $94^{\circ} \mathrm{C}, 35$ cycles of denaturing at $94^{\circ} \mathrm{C}$ for $30 \mathrm{~s}$, annealing at $55^{\circ} \mathrm{C}$ for $30 \mathrm{~s}$ and extension of $72^{\circ} \mathrm{C}$ for $30 \mathrm{~s}$ were performed, followed by a final extension step of $72^{\circ} \mathrm{C}$ for $5 \mathrm{~min}$. After it had been amplified, the $312 \mathrm{bp}$ PCR products was subjected to direct sequencing on an ABI 3700 automated DNA sequencer using a Dye Terminator Cycle sequencing kit (Applied Biosystems, Foster City, CA).

\section{Statistical analysis}

The differences in genotype distributions between patients and controls and the Hardy-Weinberg equilibrium (HWE) of each marker were analyzed using a chi-square test. Differences in age and age of onset between three groups were calculated with t-test. Allelic and genotypic frequency distributions were compared between groups by chi-square tests for independence. The univariate and multivariate logistic regression analyses were performed to evaluate the unique contribution of identified risk factors in the prediction of suicide behaviors. Possible interactions between genetic variants and other risk factors were also investigated using logistic regression analyses. Odds ratio (OR) values and 95\% confidence intervals (CI) were calculated. The results were considered nominally significant at the level of $p<$ 0.05. The SPSS package (version 13.0 for Windows; SPSS, Chicago, Illinois) was used for statistical analyses.

\section{Results}

\section{Clinical characteristics of patients}

The demographic and clinical characteristics of the patients are presented in Table 1. The study population consisted of $215 \mathrm{MDD}$ +suicide (mean age \pm SD, 33.4 \pm 11.9 years) and 215 matched MDD-suicide (mean age \pm $\mathrm{SD}, 33.6 \pm 10.8$ years). For MDD+suicide group, one hundred and seventy-one patients $(79.5 \%)$ suicided by drug overdose, hanging, drowning and 44 patients $(20.5 \%)$ suicided by violent methods such as several
Table 1 Demographic Characteristics of the MDD patients with suicide and MDD patients without suicide

\begin{tabular}{llll}
\hline & MDD+suicide & MDD-suicide & $\boldsymbol{p}$ value \\
\hline Sex (males/females) & $92 / 123$ & $92 / 123$ & \\
Age & $15 \sim 75$ & $15 \sim 77$ & 0.721 \\
(years, mean \pm SD) & $(33.4 \pm 11.9)$ & $(33.6 \pm 10.8)$ & \\
Age of onset & $14 \sim 75$ & $15 \sim 76$ & 0.565 \\
(years, mean \pm SD) & $(28.4 \pm 10.3)$ & $(29.4 \pm 10.7)$ & \\
Course of disease & 2 weeks $\sim 25$ years & 2 weeks $\sim 29$ years & 0.935 \\
(years, mean \pm SD) $(3.43 \pm 4.52)$ & $(3.39 \pm 4.54)$ & \\
HDRS scores $^{\text {a }}$ & $51.19 \pm 10.61$ & $49.87 \pm 10.49$ & 0.079 \\
\hline
\end{tabular}

${ }^{\mathrm{a}}$ HDRS, Hamilton depression rating scale for depression

deep cuts. No statistically significant differences were observed between the MDD+suicide and MDD-suicide groups for age, age at onset, course of disease or HDRS scores.

\section{Genotypes and allele frequencies in the TPH2 rs7305115 polymorphisms}

A total of 430 unrelated, major depression patients with and without suicide behaviors were genotyped for the TPH2 rs7305115 polymorphisms. The distributions of both TPH2 polymorphisms in MDD+suicide and MDDsuicide were in agreement with the Hardy-Weinberg equilibrium (HWE) applying the HWSIM computer program http://krunch.med.yale.edu/hwsim. The distributions of genotypes for TPH2 rs7305115 polymorphisms did not deviate from HWE in MDD with or without suicide groups (Table 2). Homozygous genotypes were identified by the presence of GG and AA, but the AG for heterozygous genotype (Figure 1). In the total

Table 2 Distribution of genotypes and allele frequencies of TPH2 rs7305115 polymorphism

\begin{tabular}{|c|c|c|c|c|c|}
\hline & & $\begin{array}{l}\text { MDD } \\
\text { +suicide } \\
(n=215)\end{array}$ & $\begin{array}{l}\text { MDD- } \\
\text { suicide } \\
\text { (n=215) }\end{array}$ & $P$ value $^{a}$ & $\begin{array}{l}\text { OR } \\
(95 \% \mathrm{Cl})\end{array}$ \\
\hline \multirow[t]{4}{*}{ Genotype (N, \%) } & & & & $<0.001$ & - \\
\hline & AA & 31 (14.4\%) & $63(29.3 \%)$ & & \\
\hline & $A G$ & $\begin{array}{l}118 \\
(54.9 \%)\end{array}$ & $\begin{array}{l}108 \\
(50.2 \%)\end{array}$ & & \\
\hline & GG & 66 (30.7\%) & $44(20.5 \%)$ & & \\
\hline \multirow[t]{3}{*}{ Genotype (N, \%) } & & & & $<0.001$ & 0.406 \\
\hline & AA & $31(14.4 \%)$ & $63(29.3 \%)$ & & $\begin{array}{l}(0.251- \\
0.657)\end{array}$ \\
\hline & $A G+G G$ & $\begin{array}{l}184 \\
(85.6 \%)\end{array}$ & $\begin{array}{l}152 \\
(70.7 \%)\end{array}$ & & \\
\hline \multirow[t]{3}{*}{ Allele (N, \%) } & & & & $<0.001$ & 0.603 \\
\hline & A & $\begin{array}{l}180 \\
(41.9 \%)\end{array}$ & $\begin{array}{l}234 \\
(54.4 \%)\end{array}$ & & $\begin{array}{l}(0.461- \\
0.790)\end{array}$ \\
\hline & G & $\begin{array}{l}250 \\
(58.1 \%)\end{array}$ & $\begin{array}{l}196 \\
(45.6 \%)\end{array}$ & & \\
\hline
\end{tabular}

${ }^{\mathrm{a}}$ MDD+suicide vs. MDD-suicide, Pearson chi-square test. 

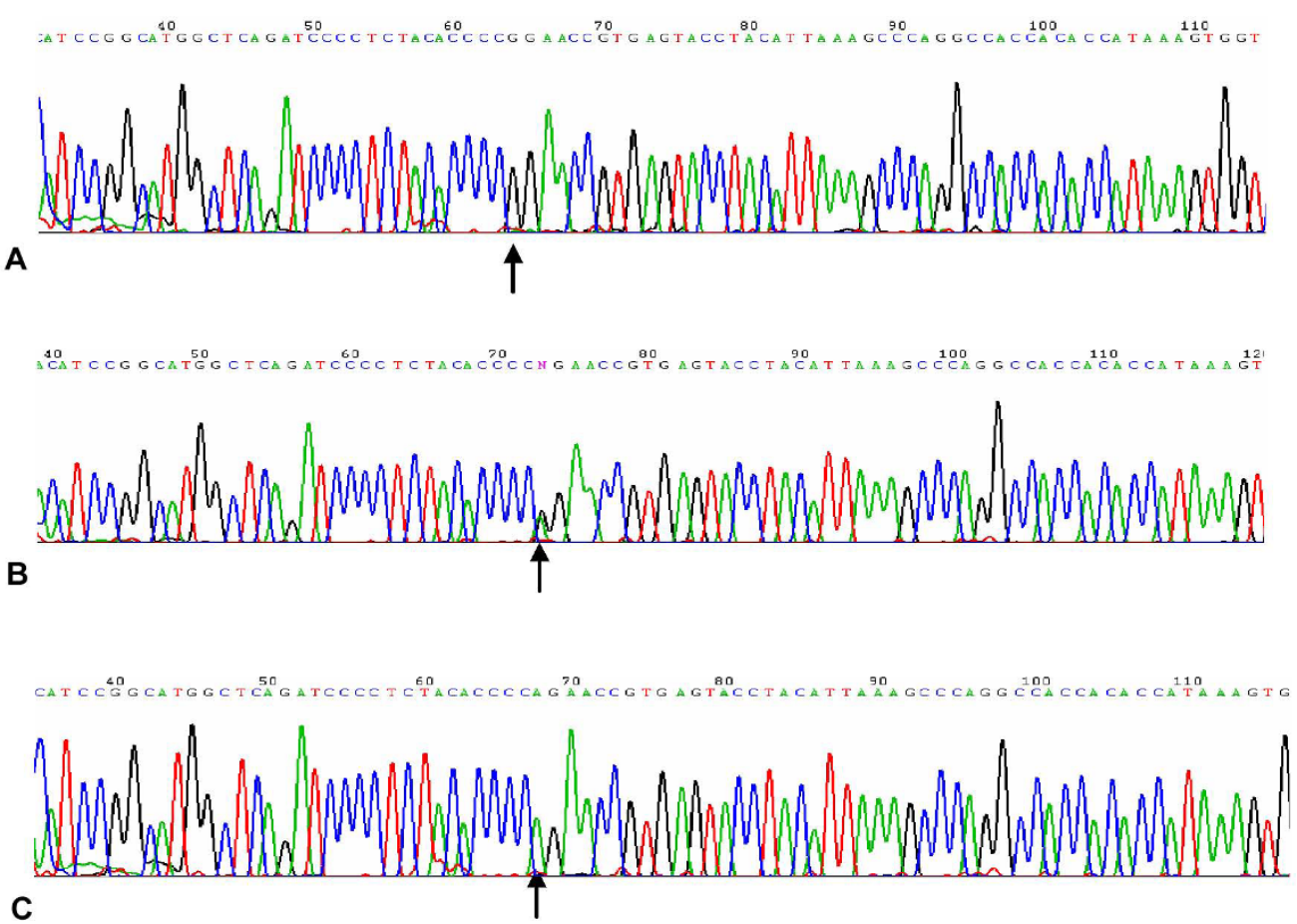

Figure 1 Schematic representation of TPH2 rs7305115 SNP. Arrows represent homozygous genotypes GG (A), AA (B) and heterozygous genotype AG (C) of TPH2 rs7305115 SNP investigated in this study.

sample, there were no significant differences between MDD+suicide and MDD-suicide in genotypic (AG and GG) frequencies for TPH2 rs7305115 polymorphisms. But the distribution of AA genotype differed significantly between MDD-suicide and MDD+suicide groups (29.3\% vs.14.4\%, $p<0.001)$. Meanwhile, the distribution of AA genotype was significantly lower than AG+GG group in MDD+suicide groups $(14.4 \%$ vs. $85.6 \%, p<$ 0.001 ). The allele distributions of both A and $G$ was significant differences between MDD+suicide and MDD-suicide in our sample. The G-allele frequency in MDD+suicide was higher than MDD-suicide (58.1\% vs.45.6\%, $p<0.001$ ), but the A-allele carrier indicated a decreased trend in MDD with suicide behaviors by compared with MDD-suicide group (41.9\% vs.54.4\%, $p<0.001)$. We suggested that the presence of the Aallele was a significant predictor for suicide behaviors because of the low frequency of the AA genotype in $\mathrm{MDD}+$ suicide group.

\section{Genotypes of TPH2 rs7305115 polymorphism and} HDRS scores in MDD+suicide group

We determined the genotypes of TPH2 rs7305115 polymorphism and HDRS scores in MDD+suicide group (Table 3). The TPH2 rs7305115 SNP was not associated with HDRS scores in sum for MDD+suicide $(p=0.092)$. But, we found that HDRS scores of cognitive impairment and hopelessness were associated with TPH2 rs7305115 genotypes among MDD+suicide $(p=$ 0.035 and $p=0.032$ ). The patients with AA genotype indicated lower HDRS scores for cognitive impairment (mean \pm SD, $7.90 \pm 3.97$ ) and hopelessness (mean \pm SD, $9.60 \pm 2.12$ ) factors than AG and GG groups in MDD with suicide behaviors. This suggested that the TPH2 rs7305115 AA could be a significant protective predictor for suicide behaviors.

Table 3 Genotypes of TPH2 rs7305115 polymorphism and HDRS scores in MDD+suicide group (scores, mean \pm SD)

\begin{tabular}{|c|c|c|c|c|}
\hline & \multicolumn{3}{|c|}{ Genotype } & \multirow{2}{*}{$\begin{array}{c}P \\
\text { value }\end{array}$} \\
\hline & AA & AG & GG & \\
\hline $\begin{array}{l}\text { Anxiety/ } \\
\text { Somatization }\end{array}$ & $12.83 \pm 4.03$ & $12.11 \pm 3.72$ & $12.01 \pm 3.83$ & 0.113 \\
\hline Loss of weight & $1.81 \pm 0.54$ & $1.78 \pm 0.54$ & $1.55 \pm 0.48$ & 0.832 \\
\hline $\begin{array}{l}\text { Cognitive } \\
\text { impairment }\end{array}$ & $7.90 \pm 3.97$ & $10.05 \pm 4.23$ & $10.93 \pm 3.82$ & 0.035 \\
\hline Diurnal change & $1.76 \pm 1.27$ & $1.67 \pm 1.26$ & $1.45 \pm 0.97$ & 0.223 \\
\hline Slow movement & $10.23 \pm 2.41$ & $9.15 \pm 2.33$ & $9.38 \pm 2.75$ & 0.468 \\
\hline Sleep disorders & $5.61 \pm 0.66$ & $5.24 \pm 0.71$ & $5.60 \pm 0.85$ & 0.176 \\
\hline Hopelessness & $9.60 \pm 2.12$ & $11.57 \pm 1.80$ & $11.29 \pm 2.10$ & 0.032 \\
\hline HDRS scores in sum & $\begin{array}{c}49.80 \pm \\
10.57\end{array}$ & $\begin{array}{c}51.49 \pm \\
10.71\end{array}$ & $\begin{array}{c}52.28 \pm \\
10.83\end{array}$ & 0.092 \\
\hline
\end{tabular}


Predictors for the suicide behaviors in MDD patients To investigate the predictive power of AA genotype of TPH2 rs7305115 polymorphisms, a univariate logistic regression analysis was performed to examine the predictive effect of each factor on the risk for behaviors in MDD patients (Table 4). The 36 potential risk factors for MDD+suicide group were compared with those of MDD-suicide group. Compared with the AG and GG groups, the AA group $(\mathrm{OR}=0.50,95 \% \mathrm{CI}=0.31-0.82$,

Table 4 Results from univariate logistic regression analysis i.e., $\mathrm{OR}$, $95 \% \mathrm{Cl}$, Wald statistic, and probability values for predictor variables of MDD suicide behaviors

\begin{tabular}{|c|c|c|c|c|}
\hline Variables & $O R$ & $95 \% \mathrm{Cl}$ & Wald & $P$ value \\
\hline Education under middle school & 2.39 & $1.62-3.52$ & 19.705 & 0.000 \\
\hline Married & 0.20 & $0.12-0.32$ & 46.600 & 0.000 \\
\hline Age of onset ( $=\geq 35$ years) & 0.79 & $0.54-1.17$ & 1.407 & 0.236 \\
\hline Short course of diseases $(=\leq 1$ year $)$ & 0.83 & $0.57-1.21$ & 0.943 & 0.332 \\
\hline Employed & 0.67 & $0.45-1.00$ & 3.809 & 0.051 \\
\hline Family history of Mental illness & 0.94 & $0.64-1.39$ & 0.086 & 0.769 \\
\hline Onset abruptly or subacute & 1.13 & $0.76-1.68$ & 0.366 & 0.545 \\
\hline Predisposing factors & 1.15 & $0.78-1.72$ & 0.500 & 0.479 \\
\hline Unhappy childhood & 1.12 & $0.70-1.80$ & 0.233 & 0.650 \\
\hline Family history of suicide & 2.58 & $1.47-4.54$ & 11.328 & 0.001 \\
\hline Physical disease & 1.15 & $0.69-1.93$ & 0.279 & 0.597 \\
\hline Monthly income $(=<\$ 40)$ & 2.02 & $1.37-2.99$ & 7.892 & 0.005 \\
\hline Smoking & 1.64 & $1.02-2.65$ & 4.164 & 0.041 \\
\hline Drinking & 1.64 & $1.07-2.53$ & 5.178 & 0.023 \\
\hline Introversion & 1.90 & $1.25-2.87$ & 9.155 & 0.002 \\
\hline Economic pressure & 2.58 & $1.64-4.05$ & 17.434 & 0.000 \\
\hline y a month ago & 0.96 & 0.65 & 0.040 & 0.841 \\
\hline Unhappy a year ago & 1.14 & $0.76-1.72$ & 0.397 & 0.529 \\
\hline Unhappy after a year & 0.87 & $0.60-1.31$ & 0.362 & 0.547 \\
\hline Friend suicide two weeks ago & 1.11 & $0.46-2.66$ & 0.050 & 0.823 \\
\hline Friend suicide a year ago & 1.22 & & 0.295 & 0.587 \\
\hline Negative life events half vear age & 5.74 & $\begin{array}{l}3.28- \\
10.04\end{array}$ & 43.365 & 0.000 \\
\hline Family emotional support needed & 0.43 & $0.26-0.72$ & 10.587 & 0.001 \\
\hline Family emotional support gained & 1.06 & $0.72-1.55$ & 0.086 & 0.769 \\
\hline Friends' emotional support needed & 0.38 & $0.24-0.60$ & 16.025 & 0.000 \\
\hline Friends' emotional support gained & 1.06 & $0.72-1.55$ & 0.084 & 0.772 \\
\hline Depression $(\mathrm{HDRS}=\geq 35)^{\mathrm{a}}$ & 1.58 & $1.07-2.34$ & 5.227 & 0.020 \\
\hline Hopelessness $(\mathrm{HDRS}=\geq 6)^{a}$ & 7.68 & $\begin{array}{l}4.99- \\
11.83\end{array}$ & 93.755 & 0.000 \\
\hline Anxiety/Somatization(HDRS $=>7)^{a}$ & 0.84 & $0.56-1.27$ & 0.706 & 0.401 \\
\hline Loss of weight in a week $(=0.5 \mathrm{~kg})$ & 0.93 & $0.64-1.36$ & 0.149 & 0.699 \\
\hline Cognitive impairment(HDRS $=>12)^{a}$ & 1.17 & $0.77-1.78$ & 0.553 & 0.457 \\
\hline Diurnal change $(\mathrm{HDRS}=\geq 1)^{a}$ & 1.12 & $0.76-1.66$ & 0.350 & 0.554 \\
\hline Slow movement $(H D R S=\geq 8)^{\text {a }}$ & 1.12 & $1.77-4.64$ & 0.340 & 0.560 \\
\hline Sleep disorders $(\mathrm{HDRS}=\geq 2)^{a}$ & 3.28 & $2.20-4.88$ & 35.128 & 0.000 \\
\hline Anxiety $(\text { HAMA }=\geq 21)^{b}$ & 4.12 & $2.54-6.68$ & 35.622 & 0.000 \\
\hline TPH2 rs7305115 AA & 0.50 & $0.31-0.82$ & 13.941 & 0.000 \\
\hline
\end{tabular}

${ }^{a}$ HDRS, Hamilton depression rating scale for depression;

${ }^{b}$ HAMA, Hamilton anxiety scale for anxiety $p<0.001)$ were at lower risk for suicide attempts. The TPH2 polymorphism emerged as a significant variable that could reliably predict clinical suicide behaviors.

Significant risk factors were entered into a forward selection multivariate logistic regression analysis. The involvement of sixteen factors in MDD+suicide was analyzed using multiple logistic regression analysis. Using this model, the degree of involvement of each factor for suicide patients could be estimated (Table 5). On multivariate analysis, the final model indicated that TPH2 rs7305115 AA (OR 0.33, 95\% CI 0.22-0.99, P < 0.001), family history of suicide (OR 2.98, 95\% CI 1.17-5.04, P < 0.001 ), negative life events half year ago (OR 6.64, 95\% CI 2.48-11.04, P $<0.001$ ) and hopelessness (OR 7.68, 95\% CI 5.79-13.74, $\mathrm{P}<0.001)$ were significantly associated with the suicide behaviors in MDD patients. The TPH2 rs7305115A remained a significant protective predictor of suicide behaviors.

Further, we examined the interactions between TPH2 genotypes and the potential three factors on the risk for MDD+suicide group (Table 6). The results indicated that family history of suicide, negative life events half year ago and hopelessness were significantly associated with TPH2 genotypes in MDD+suicide patients ( $p=$ $0.006, p=0.005$, and $p=0.002$, respectively).

\section{Discussion}

Suicide receives increasing attention worldwide, with many countries developing national strategies for prevention. Rates of suicide vary greatly between countries, with the greatest burdens in developing countries [22]. Most people who die by suicide have psychiatric disorders, notably mood, substance-related, anxiety, psychotic, and personality disorders, with comorbidity being common [23]. Risk for suicide may have genetic contributions, however, specific genes or relevant DNA sequence variations have not yet been identified [24]. Therefore, it is a major research challenge to clarify the relative heritability of the risk for suicide, in particular, separately from the heritability of disorders or traits that are strongly associated with suicidal risk [25].

The rate-limiting enzyme of serotonin biosynthesis, $\mathrm{TPH} 2$, is one of the most promising candidate genes for psychiatric disorders [26]. In the present study, we

Table 5 Results from multivariate logistic regression analysis for predictor variables of MDD+suicide group

\begin{tabular}{lllll}
\hline Variables & OR & $\mathbf{9 5 \%} \mathbf{C l}$ & Wald & $\boldsymbol{P}$ value \\
\hline TPH2 rs7305115 AA & 0.33 & $0.22-0.99$ & 12.861 & $\mathbf{0 . 0 0 0}$ \\
Family history of suicide & 2.98 & $1.17-5.04$ & 10.228 & $\mathbf{0 . 0 0 1}$ \\
Negative life events half year ago & 6.64 & $2.48-11.04$ & 41.145 & $\mathbf{0 . 0 0 0}$ \\
Hopelessness (HDRS $>=6)^{a}$ & 7.68 & $5.79-13.74$ & 90.235 & $\mathbf{0 . 0 0 0}$ \\
\hline
\end{tabular}

${ }^{\mathrm{a}}$ HDRS, Hamilton depression rating scale for depression 
Table 6 Association analysis of TPH2 genotypes and predictor variables in MDD+suicide group

\begin{tabular}{|c|c|c|c|c|}
\hline & & Genotyp & & $P$ value ${ }^{a}$ \\
\hline & $A A(n=31)$ & AG $(n=118)$ & GG $(n=66)$ & \\
\hline Family history of suicide & & & & 0.006 \\
\hline Yes & 5 & 45 & 33 & \\
\hline No & 26 & 73 & 33 & \\
\hline Negative life events half year ago & & & & 0.005 \\
\hline Yes & 10 & 51 & 42 & \\
\hline No & 21 & 67 & 24 & \\
\hline Hopelessness & & & & 0.002 \\
\hline Yes & 17 & 86 & 58 & \\
\hline No & 14 & 32 & 8 & \\
\hline
\end{tabular}

a Pearson chi-square test.

investigated TPH2 rs7305115 variants in a Han sample of suicide attempters, and compared them to non-suicidal depressed patients. We also investigated the association of polymorphisms with the life environment factors among suicide patients. The issue of association of TPH2 SNPs with suicide-related behavior is a complex and controversial one. Several studies have indicated possible associations between various TPH2 polymorphisms and major depression, suicidal behavior [12,27]. In contrast, other studies failed to find associations between TPH2 polymorphisms and suicidality [28,29]. Nevertheless, we found an association of suicidal behavior with the TPH2 rs7305115 SNP in the present study. Our data shows that MDD+suicide patients have low frequencies of the rs7305115 A-allele and AA genotypes (OR =0.50).

Studies indicated that a history of suicide attempt, a psychiatric condition such as ongoing major depression, alcohol or other substance use disorder, hopelessness, separation or loss, anger, and suicidal ideation have been implicated as predictors of suicidal behaviors $[30,31]$. The MDD patients with greater levels of hopelessness also were prone to the multiple suicide attempts [32]. Our findings indicated that cognitive impairment and hopelessness were associated with TPH2 rs7305115 SNP among MDD+suicide patients.

The multivariate analysis indicated that four factors (TPH2, family history of suicide, negative life events half year ago and hopelessness) were significantly associated with the suicide behaviors in MDD patients. The TPH2 rs7305115 AA remained a significant protective predictor of suicide behaviors $(\mathrm{OR}=0.33)$. The results suggested that $\mathrm{A} \rightarrow \mathrm{G}$ mutation carriers of TPH2 rs7305115 SNP could be a higher risk of suicide attempts than AA homozygous genotype carriers in MDD patients. To identify the functional locus, it will be important to closely evaluate the significance of sequence variants in coding regions that could alter gene expression at the DNA or RNA levels.

\section{Limitations}

A number of limitations may be relevant to these studies. First, we only paid attention on a SNP maker of the TPH2 gene in the current study. More TPH2 marker will be examined for MDD patients with suicide behaviors in the future study. Further, we had no the detail mechanistic explanation regarding the role of serotonin functioning in depression for TPH2 SNP. Further study is needed to elucidate its mechanism. Understanding why the vulnerability to suicide differs among MDD patients could assist in improved screening of high risk patients and treatment.

\section{Conclusions}

In case-control association studies, our findings suggested that the rs7305115 SNP in the TPH2 gene could be a marker for the genetic susceptibility to suiciderelated traits in Chinese. The TPH SNP might influence suicide-related traits in behaviorally extreme populations and included an independent high risk clinical sample, suicide attempters. We suggested that TPH2 gene could regulate serotonergic system and contribute to the vulnerability to suicidal behavior.

\section{Abbreviations \\ DSM: The Diagnostic and Statistical Manual of Mental Disorders; HDRS: Hamilton Depression Rating Scale; SCID-I: Structured Clinical Interview for DSM-IV Axis I Disorders; SCID-II: Structured Clinical Interview for DSM-IV Personality Disorders; 5-HT: 5-hydroxytryptamine; TPH2: the tryptophan hydroxylase-2; MDD: major depressive disorders; HWE: Hardy-Weinberg equilibrium.}

\section{Acknowledgements}

This research was supported by the "333 Project" of Jiangsu province, China (No. CA051001-6; WZD0605; CSZ00721) and Science and Technology Planning Project of Changzhou Municipality, China (No. CS2008214).

\section{Author details}

${ }^{1}$ Wuxi Psychiatric Hospital, Nanjing Medical University, Wuxi, China. ${ }^{2}$ Ankang Hospital, Jining, China. ${ }^{3}$ Clinical Oncology Laboratory, Changzhou Tumor Hospital, Medical College of Suzhou University, Changzhou, China.

${ }^{4}$ Department of Molecular Epidemiology, Shantou University Medical College, Shantou, China. 


\section{Authors' contributions}

JY, ZC, and CL carried out the molecular genetic studies, participated in the sequence alignment and drafted the manuscript. QL, GW, GS, YC, YL, and KL recruited the Subjects. CZ and GY participated in the design of the study and performed the statistical analysis. $Y Z$ conceived of the study, and participated in its design and coordination and helped to draft the manuscript. All authors read and approved the final manuscript.

\section{Competing interests}

The authors declare that they have no competing interests.

Received: 25 June 2010 Accepted: 25 August 2010

Published: 25 August 2010

\section{References}

1. Li X, Xiao Z, Xiao S: Suicide among the elderly in mainland China. Psychogeriatrics 2009, 9:62-66.

2. Witte TK, Timmons KA, Fink E, Smith AR, Joiner TE: Do major depressive disorder and dysthymic disorder confer differential risk for suicide? J Affect Disord 2009, 115:69-78.

3. Roy A, Sarchiopone M, Carli V: Gene-environment interaction and suicidal behavior. J Psychiatr Pract 2009, 15:282-288.

4. Arango V, Huang YY, Underwood MD, Mann JJ: Genetics of the serotonergic system in suicidal behavior. J Psychiatr Res 2003, 37:375-386.

5. Anguelova M, Benkelfat $C$, Turecki $G$ : A systematic review of association studies investigating genes coding for serotonin receptors and the serotonin transporter: II. Suicidal behavior. Mol Psychiatry 2003, 8:646-653.

6. Savelieva KV, Zhao S, Pogorelov VM, Rajan I, Yang Q, Cullinan E, Lanthorn TH: Genetic disruption of both tryptophan hydroxylase genes dramatically reduces serotonin and affects behavior in models sensitive to antidepressants. PLoS One 2008, 3:e3301.

7. Mann JJ: Role of the serotonergic system in the pathogenesis of major depression and suicidal behavior. Neuropsychopharmacology 1999, 21:99S-105S

8. Walther DJ, Peter JU, Bashammakh S, Hortnagl H, Voits M, Fink H, Bader M: Synthesis of serotonin by a second tryptophan hydroxylase isoform. Science 2003, 299:76.

9. Patel PD, Pontrello C, Burke S: Robust and tissue-specific expression of TPH2 versus TPH1 in rat raphe and pineal gland. Biol Psychiatry 2004, 55:428-433.

10. Cote F, Thevenot E, Fligny C, Fromes $Y$, Darmon M, Ripoche MA, Bayard E, Hanoun N, Saurini F, Lechat P, et al: Disruption of the nonneuronal tph1 gene demonstrates the importance of peripheral serotonin in cardiac function. Proc Natl Acad Sci USA 2003, 100:13525-13530.

11. Zhang X, Beaulieu JM, Sotnikova TD, Gainetdinov RR, Caron MG: Tryptophan hydroxylase-2 controls brain serotonin synthesis. Science 2004, 305:217.

12. Zill $P$, Baghai TC, Zwanzger $P$, Schule $C$, Eser D, Rupprecht $R$, Moller HJ, Bondy B, Ackenheil M: SNP and haplotype analysis of a novel tryptophan hydroxylase isoform (TPH2) gene provide evidence for association with major depression. Mol Psychiatry 2004, 9:1030-1036.

13. Scheuch K, Lautenschlager M, Grohmann M, Stahlberg S, Kirchheiner J, Zill P, Heinz A, Walther DJ, Priller J: Characterization of a functional promoter polymorphism of the human tryptophan hydroxylase 2 gene in serotonergic raphe neurons. Biol Psychiatry 2007, 62:1288-1294.

14. Lopez de Lara C, Brezo J, Rouleau G, Lesage A, Dumont M, Alda M, Benkelfat C, Turecki G: Effect of tryptophan hydroxylase-2 gene variants on suicide risk in major depression. Biol Psychiatry 2007, 62:72-80.

15. Chen GL, Vallender EJ, Miller GM: Functional characterization of the human $\mathrm{TPH} 25^{\prime}$ regulatory region: untranslated region and polymorphisms modulate gene expression in vitro. Hum Genet 2008, 122:645-657.

16. Lin YM, Ko HC, Chang FM, Yeh TL, Sun HS: Population-specific functional variant of the $\mathrm{TPH} 2$ gene $2755 \mathrm{C}>\mathrm{A}$ polymorphism contributes risk association to major depression and anxiety in Chinese peripartum women. Arch Womens Ment Health 2009, 12:401-408.

17. Leung CM, Wing YK, Kwong PK, Lo A, Shum K: Validation of the ChineseCantonese version of the hospital anxiety and depression scale and comparison with the Hamilton Rating Scale of Depression. Acta Psychiatr Scand 1999, 100:456-461.
18. Williams JB: A structured interview guide for the Hamilton Depression Rating Scale. Arch Gen Psychiatry 1988, 45:742-747.

19. Baca-Garcia E, Perez-Rodriguez MM, Basurte-Villamor I, Fernandez del Moral AL, Jimenez-Arriero MA, Gonzalez de Rivera JL, Saiz-Ruiz J, Oquendo MA: Diagnostic stability of psychiatric disorders in clinical practice. Br J Psychiatry 2007, 190:210-216.

20. Spitzer RL, Wakefield JC: DSM-IV diagnostic criterion for clinical significance: does it help solve the false positives problem? Am J Psychiatry 1999, 156:1856-1864.

21. Denning DG, Conwell Y, King D, Cox C: Method choice, intent, and gender in completed suicide. Suicide Life Threat Behav 2000, 30:282-288.

22. Wasserman D, Terenius L, Wasserman J, Sokolowski M: The 2009 Nobel conference on the role of genetics in promoting suicide prevention and the mental health of the population. Mol Psychiatry 2010, 15:12-17.

23. Hawton K, van Heeringen K: Suicide. Lancet 2009, 373:1372-1381.

24. Brezo J, Klempan T, Turecki G: The genetics of suicide: a critical review of molecular studies. Psychiatr Clin North Am 2008, 31:179-203.

25. Bondy B, Buettner A, Zill P: Genetics of suicide. Mol Psychiatry 2006 , 11:336-351.

26. Invernizzi RW: Role of TPH-2 in brain function: news from behavioral and pharmacologic studies. J Neurosci Res 2007, 85:3030-3035.

27. Zhou Z, Roy A, Lipsky R, Kuchipudi K, Zhu G, Taubman J, Enoch MA Virkkunen M, Goldman D: Haplotype-based linkage of tryptophan hydroxylase 2 to suicide attempt, major depression, and cerebrospinal fluid 5-hydroxyindoleacetic acid in 4 populations. Arch Gen Psychiatry 2005, 62:1109-1118.

28. De Luca V, Mueller DJ, Tharmalingam S, King N, Kennedy JL: Analysis of the novel TPH2 gene in bipolar disorder and suicidality. Mol Psychiatry 2004, 9:896-897.

29. De Luca V, Voineskos D, Wong GW, Shinkai T, Rothe C, Strauss J, Kennedy JL: Promoter polymorphism of second tryptophan hydroxylase isoform (TPH2) in schizophrenia and suicidality. Psychiatry Res 2005, 134:195-198.

30. Oquendo MA, Galfalvy H, Russo S, Ellis SP, Grunebaum MF, Burke A, Mann JJ: Prospective study of clinical predictors of suicidal acts after a major depressive episode in patients with major depressive disorder or bipolar disorder. Am J Psychiatry 2004, 161:1433-1441.

31. Beevers CG, Miller IW: Perfectionism, cognitive bias, and hopelessness as prospective predictors of suicidal ideation. Suicide Life Threat Behav 2004, 34:126-137.

32. Esposito C, Spirito A, Boergers J, Donaldson D: Affective, behavioral, and cognitive functioning in adolescents with multiple suicide attempts. Suicide Life Threat Behav 2003, 33:389-399.

doi:10.1186/1744-9081-6-49

Cite this article as: Zhang et al:: Effect of Tryptophan Hydroxylase-2 rs7305115 SNP on suicide attempts risk in major depression. Behavioral and Brain Functions 2010 6:49.

\section{Submit your next manuscript to BioMed Central and take full advantage of:}

- Convenient online submission

- Thorough peer review

- No space constraints or color figure charges

- Immediate publication on acceptance

- Inclusion in PubMed, CAS, Scopus and Google Scholar

- Research which is freely available for redistribution 